the event of a life-threatening deterioration. However, when patients were asked about EOL communication with their in-hospital care providers, only $8(6.5 \%)$ reported receiving a disclosure of prognosis, 37 (30.1\%) received information about comfort measures to control symptoms, 15 (12.2\%) were asked what was important to them when considering decisions about EOL care, and $16(13.0 \%)$ had discussed the risks and benefi ts of life-sustaining treatments (LST) with a physician. In family members who were asked about EOL communication regarding their relative (the patient), $12(15.6 \%)$ received a disclosure of prognosis, $24(31.2 \%)$ received information about comfort measures, $12(15.6 \%)$ were asked what was important to them when considering decisions about EOL care for their relative, and $11(14.3 \%)$ had discussed risks and benefi ts of LST with a physician. There are many opportunities to improve the quality of EOL communication and decision-making with seriously ill hospitalised patients and their families.

77 OPPORTUNITIES TO IMPROVE END-OF-LIFE

\title{
COMMUNICATION AND DECISION-MAKING FOR SERIOUSLY ILL HOSPITALISED PATIENTS AND THEIR FAMILIES
}

JJ You*,1 DK Heyland,2 P Dodek,3 F Lamontagne,4 D Barwich,5 C Tayler,5 P Porterfield,3 J Simon,6 Bert Enns.6 1McMaster University, Hamilton; 20ueen's University, Kingston; 3University of British Columbia, Vancouver; 4Université de Sherbrooke, Sherbrooke; 5Fraser Health Authority, Surrey; 6University of Calgary, Calgary; all in Canada.

10.1136/bmjspcare-2012-000250.75

In face-to-face interviews with seriously ill patients and/or their family members, we used a validated questionnaire to assess key components of in-hospital end-of-life (EOL) communication and decision-making at 11 Canadian hospitals. We report preliminary data from 123 seriously ill hospitalised patients (age $80 \pm 9$ years, mean \pm SD) and 77 family members (age $62 \pm 13$ years). Patients rated being comfortable and minimising suffering as $8.8 \pm 2.5$ ( $1=$ not at all important; $10=$ very important) and avoidance of being attached to machines as 7.5 \pm 3.5 . Nearly $50 \%$ of participants reported that a decision was made in hospital about the use of life-sustaining treatments (LST) in 